\title{
EL PODER CONSTITUYENTE EN LA TRADICIÓN CONSTITUCIONAL AMERICANA. EL LEGADO PROBLEMÁTICO DE LOS ESCRITOS FEDERALISTAS
}

\author{
THE CONSTITUENT POWER IN THE AMERICAN CONSTITUTIONAL \\ TRADITION. THE PROBLEMATIC LEGACY OF THE FEDERALIST \\ PAPERS
}

\section{Gabriel L. Negretto*}

\begin{abstract}
RESUMEN: Los escritos federalistas propusieron un modelo de gobierno en el que la participación de los ciudadanos no es necesaria ni conveniente para introducir cambios a la Constitución. Los legisladores y los jueces serían los responsables de adaptarla a contextos cambiantes. Sin embargo, la posibilidad de involucrar a los ciudadanos en una reforma extralegal del sistema político permaneció siempre latente en el principio de soberanía popular que los federalistas utilizaron para justificar la legitimidad de la Constitución de Filadelfia. Esta situación nunca se presentó en la experiencia constitucional americana a nivel federal pero ha sido frecuente en democracias que siguen el legado de los federalistas norteamericanos y enfrentan demandas de reforma institucional profunda. En este escenario, que prima hoy en varios países de América Latina, se torna imprescindible repensar un sistema de revisión constitucional que no brinda a los ciudadanos canales de participación para alterar o sustituir la Constitución de forma pacífica y legal.
\end{abstract}

Palabras clave: Escritos federalistas, poder constituyente, revisión constitucional, cambio constitucional extralegal, participación ciudadana, América Latina.

ABSTRACT: The Federalist Papers proposed a model of government in which the participation of citizens is either unnecessary or inconvenient to make constitutional revisions. Legislators and judges would be responsible for adapting the constitution to changing environments. However, the possibility of involving citizens in an extra-legal reform of the political system remained always latent in the principle of popular sovereignty that the Federalists used to justify the legitimacy of the Philadelphia constitution. This situation never materialized in the American constitutional experience at the federal level but has been frequent in democracies that follow the legacy of the Federalists and face demands of radical institutional reform. In this scenario, which prevails today in several Latin American countries, it is imperative to rethink a system of constitutional revisions that deprives citizens of channels of participation to alter or replace the constitution in a peaceful and legal manner.

Key words: Federalist Papers, constituent power, constitutional revision, extra-legal constitutional change, citizen participation, Latin America.

\footnotetext{
Abogado (Universidad de Buenos Aires, Argentina), Master of International Affairs (Columbia University, EE.UU.), PhD in Political Science (Columbia University, EE.UU.). Profesor, División de Estudios Políticos, Centro de Investigación y Docencia Económicas, México D.F. Dirección postal: Carretera México-Toluca 3655, Lomas de Santa Fe, México D.F. 0210 . Dirección electrónica: gabriel.negretto@cide.edu. Agradezco a Claudio López-Guerra, Juan Bertomeu, Joel Colon-Ríos, Andrea Pozas-Loyo, Carlos Bravo Regidor, Rodolfo Vázquez y revisores anónimos de esta revista por sus comentarios a versiones anteriores de este trabajo.
} 


\section{INTRODUCCIÓN}

En su discurso de despedida, George Washington argumentó que si bien el derecho del pueblo de establecer o alterar la Constitución era el fundamento del sistema de gobierno creado en su país en 1787, la Constitución vigente debía ser sagradamente obligatoria para todos hasta que un acto explícito y auténtico del pueblo la cambiara ${ }^{1}$. Esta afirmación encierra una paradoja. Si un principio fundamental del gobierno republicano es el derecho del pueblo de crear y cambiar la Constitución bajo la cual vive, este derecho se puede ejercer aun cuando la Constitución omita declararlo. Sin embargo, si la Constitución no regula este derecho, entonces su ejercicio es extralegal y contrariamente a lo que afirma Washington, la Constitución vigente no es vinculante para juzgar sobre la validez del procedimiento que lo hace efectivo.

Esta paradoja tiene origen en el tipo de gobierno constitucional que propusieron los escritos federalistas. La legitimidad de la Constitución de Filadelfia, sancionada irregularmente en relación al sistema constitucional precedente, se fundó en la necesidad de resolver la crisis que este último experimentaba y en la ratificación de la nueva Constitución por el pueblo de los distintos estados reunidos en convenciones locales. Dado que la validez de la nueva Constitución descansaba en el consentimiento de los gobernados, hubiese sido lógico pensar que el cuerpo ciudadano obtendría alguna prerrogativa legal para actuar en protección de la Constitución, peticionar la alteración o el reemplazo de la misma, o consentir a estos cambios cuando fueran propuestos por los poderes constituidos. Sin embargo, el proyecto federalista buscó excluir la participación ciudadana en materia de cambios constitucionales y relegar el derecho colectivo del pueblo de alterar o reemplazar la Constitución a momentos revolucionarios que por definición ocurren al margen de la ley.

El silencio de la Constitución en esta materia crea un problema político y legal que puede terminar obstaculizando un reemplazo constitucional apoyado por la ciudadanía o bien permitir que el mismo se realice de manera manipuladora y autointeresada por parte de alguno de los poderes constituidos. Este problema nunca se presentó en el constitucionalismo americano a nivel federal pero ha sido frecuente en democracias que siguen el legado de los federalistas norteamericanos y enfrentan demandas de reforma institucional profunda. En este escenario, que prima hoy en varios países de América Latina, resulta imprescindible adoptar un sistema de revisión constitucional que otorgue a los ciudadanos el derecho de participar legalmente en transformaciones constitucionales profundas y al mismo tiempo dificulte que los representantes utilicen en su beneficio la invocación a un poder constituyente abstracto.

Este trabajo comienza con un análisis del concepto de poder constituyente defendido por los federalistas para justificar el actuar de la convención de Filadelfia. Luego se contrasta este concepto con la exclusión de la ciudadanía en materia de alteraciones a la Constitución. La sección siguiente analiza los argumentos vertidos por distintos autores en relación a la posibilidad lógica y los precedentes históricos de formas extralegales de participación ciudadana en cambios constitucionales. Luego se discute la importancia de dar

\footnotetext{
1 Ver Discurso de Despedida del 19 de septiembre de 1796, en Washington (1997) pp. 962-977.
} 
cauce institucional a esta participación a la luz de la experiencia latinoamericana reciente. Se culmina con una breve reflexión acerca de la relevancia de este tema para la teoría constitucional y el derecho constitucional comparado.

\section{LA TEORÍA DEL PODER CONSTITUYENTE EN LOS ESCRITOS FEDERALISTAS}

La teoría del poder constituyente democrático se funda en tres proposiciones lógicamente encadenadas: 1) la legitimidad y la validez de una Constitución deriva de haber sido creada con la autorización o el consentimiento de los gobernados, 2) dado que la Constitución es creada por medio de un acto de soberanía popular, los poderes constituidos carecen de autoridad para transgredir los límites impuestos por la Constitución, y 3) los gobernados se reservan en forma permanente el derecho de alterar o sustituir la Constitución cuando lo consideren necesario para promover el bienestar general ${ }^{2}$. Si bien esta teoría se suele asociar a la revolución francesa y los escritos de Sieyès, lo cierto es que su formulación apareció durante la revolución americana, primero de manera implícita en la Declaración de la Independencia, y luego de manera más precisa en varias de las nuevas constituciones que se crearon en los estados americanos después de $1776^{3}$. La elaboración de la idea del pueblo como sujeto del poder constituyente fue parcial, intermitente y fragmentada, pero puede verse de manera más o menos clara en los escritos de políticos e intelectuales como James Wilson, Thomas Paine y Thomas Jefferson.

Sin embargo, a pesar de que la revolución americana dejó como legado indiscutible la idea de que el pueblo es el único sujeto legitimado para crear una Constitución republicana, no fue igual de claro el significado que tendría la participación de los gobernados en la modificación o reemplazo futuro de esa misma Constitución. La proposición de que el cuerpo ciudadano retiene el derecho de alterar o cambiar la Constitución, generó disputas en torno a dos puntos fundamentales. El primero fue si ese derecho requiere reconocimiento constitucional expreso o bien se halla implícito en los principios del gobierno republicano. El segundo, si ese derecho se ejerce solo bajo condiciones revolucionarias, es decir, cuando el gobierno se torna opresivo y tiránico, o si es posible invocar el mismo para ser ejercido de manera pacífica en condiciones políticas normales. Las posiciones tomadas en torno a estas cuestiones dieron lugar a dos interpretaciones opuestas acerca de los alcances de la idea del poder constituyente.

De acuerdo a una visión radical, el pueblo tiene un derecho inherente de cambiar su Constitución y, en un gobierno republicano, lo puede ejercer de manera legal aún en ausencia de regulación constitucional. No se requiere que existan las condiciones de opresión extrema que justifican a una revolución para ejercer este derecho. Para una visión más moderada o conservadora, después de la fundación de una república el pueblo solo tiene aquellos derechos de participación que la Constitución le reconoce explícitamente. Por esta razón, la única circunstancia bajo la cual se podría alterar o reemplazar la Constitución en

2 Sobre la teoría del poder constituyente, ver Kalyvas (2005) y Colon-Ríos (2012).

3 Palmer (1970). 
transgresión a la misma sería una revolución, que por definición es extralegal ${ }^{4}$. La visión radical del poder constituyente predominó durante la elaboración de las primeras constituciones posteriores a la independencia y sobrevivió por largo tiempo en la tradición constitucional de los estados. La visión conservadora, en cambio, se impuso a nivel federal luego de la sanción de la Constitución de Filadelfia, sobre todo a través de la filosofía propagada por los escritos de El Federalista (EF desde ahora)

El texto clave sobre este tema fue el EF \# 40, en el que Madison defiende el proceder de la convención de Filadelfia contra las acusaciones de ilegalidad en el ejercicio de su mandato. Como es sabido, la convención actuó irregularmente en tres aspectos: produjo una nueva Constitución en vez de una revisión a los Artículos de la Confederación, estableció un procedimiento de ratificación en el cual era suficiente el consentimiento de 9 de los 13 estados, en vez de la unanimidad que requería el artículo XIII de la Constitución existente, y se sustituyeron las legislaturas estatales que preveía el mismo artículo por convenciones locales ratificadoras. En el mencionado Federalista \# 40 Madison utiliza varios argumentos para minimizar el carácter irregular del proceder de la convención, pero en última instancia concede que la misma no se apegó puntillosamente a las formalidades que exigía la Constitución precedente para su enmienda. Y es en este punto donde ofrece la principal justificación de la validez de la nueva Constitución.

Madison argumenta ${ }^{6}$ que toda vez que grandes cambios son necesarios, una estricta adherencia a las formas no puede ser utilizada para desvirtuar "el precioso derecho" del pueblo de abolir o alterar sus gobiernos como mejor le convenga. Este derecho colectivo, emblemático de la revolución americana y consagrado en la Declaración de Independencia de 1776, incluye lógicamente la prerrogativa de darse una nueva Constitución. Ahora bien, como el pueblo no tiene la capacidad espontánea de actuar unánimemente y en forma directa para crear un nuevo orden constitucional, es esencial que esos grandes cambios ocurran por medio de propuestas "informales y no autorizadas" que un grupo de ciudadanos le hace a la población en general en cumplimento de su deber patriótico. El hecho de que una propuesta de cambio constitucional pensada para promover el bienestar general haya carecido de autorización y asidero legal en el régimen constitucional precedente no encierra para Madison ningún riesgo, dado que la misma carece de validez hasta que sea aprobada por el pueblo. Y esa aprobación, en caso de darse, remedia cualquier irregularidad precedente que haya existido en el procedimiento.

La idea de que la validez de la nueva Constitución descansaría en la aprobación del pueblo y no en haber seguido estrictamente los procedimientos para la enmienda de los Artículos de la Confederación fue un argumento clave de los federalistas en su lucha por lograr la ratificación del nuevo esquema de gobierno. En EF \# 43, por ejemplo, al justificar que la ratificación de las convenciones de 9 estados sería suficiente para establecer la Constitución, Madison argumenta que la regla de unanimidad hubiese sido arbitraria. Dado que

\footnotetext{
4 Sobre la existencia de dos visiones opuestas acerca del significado de la soberanía popular en la tradición constitucional americana, ver FrITz (1997).

5 La edición que se utilizará para las citas de todos los escritos de El Federalista es la de Penguin, The Federalist Papers (1987).

6 El Federalista (1987) p. 264.
} 
solo la autoridad expresa del pueblo puede dar debida validez a la Constitución, condicionar los intereses esenciales de todos al capricho o corrupción de un solo miembro hubiese frustrado la manifestación de una voluntad común 7 . También Hamilton insiste sobre este tema en EF \# 22, sosteniendo que la debilidad de los Artículos de la Confederación derivó en gran medida de no haberse sancionado por medio de la ratificación del pueblo, que en ese caso hubiese sido base de su legitimidad ${ }^{8}$.

En la práctica política, sin embargo, los federalistas cuidaron de no recaer exclusivamente en el consentimiento directo del pueblo para apartarse del proceso de enmienda vigente. Como bien señalan Ackerman y $\mathrm{Katyal}^{9}$, la estrategia de los federalistas consistió en moverse en un limbo entre apelar a la ruptura revolucionaria y obtener el apoyo de las instituciones existentes, en particular el Congreso, para crear nuevas reglas ${ }^{10}$. Esto puede verificarse en el hecho de que la propia convención fue convocada originalmente por el Congreso Continental y que este mismo Congreso fue el conducto por el cual se envió el proyecto federalista a ratificación de los estados y se declararon cumplidos los requisitos de aprobación de la nueva Constitución.

Por otra parte, durante el proceso de ratificación, la expresión de la voluntad popular fue canalizada de manera institucional y representativa. Esto marcó una diferencia importante entre el legado de la revolución americana y francesa. Mientras que para Sieyès la nación se hallaba siempre en estado de naturaleza, para los federalistas el pueblo era una entidad preconstituida en la organización institucional de las colonias ${ }^{11}$. De manera consistente con esta idea, Madison propuso en EF \#39 que a los efectos del proceso de ratificación de la nueva Constitución, el pueblo no sería considerado como individuos aislados miembros de una nación, sino como parte de los distintos estados independientes a los que pertenecían $^{12}$. Asimismo, los miembros de cada estado no votarían directamente por la Constitución en un referendo para aprobar o rechazar el proyecto sino por medio de delegados electos para integrar una convención especialmente formada al efecto. Si bien muchas de estas convenciones tomarían decisiones por regla de mayoría, el solo hecho de reunirse en cada estado y que nueve de ellas deberían aprobar el proyecto, aseguraba conducir la participación popular por medio de una organización descentralizada que daría un grado de inclusión y deliberación importante al proceso.

Se podría pensar que sustituir las legislaturas estatales por convenciones especialmente electas fue una mera decisión estratégica de los federalistas para minimizar el previsible rechazo de los órganos constituidos locales, que perderían posiciones en el nuevo arreglo. Sin embargo, el uso del mecanismo de la convención para crear un nuevo orden constitucional era parte integral de una visión del poder constituyente que ya tenía carta de legiti-

\footnotetext{
El Federalista (1987) p. 285.

8 El Federalista (1987) p. 183.

9 Ackerman y Katyal (1995).

10 Ver también sobre este punto Frank (2007) p. 111, quien argumenta que esta vía intermedia entre el apego positivista a la ley y una apelación abiertamente extralegal al pueblo como entidad abstracta ilustra la visión que tenía Madison acerca del ejercicio adecuado del poder constituyente.

11 Arendt (1963) p. 165.

12 El Federalista (1987) pp. 256-257.
} 
NegretTo, Gabriel L. — "El poder constituyente en la tradición constitucional americana..."

midad en algunos estados y gozaba de aceptación en la doctrina constitucional de la época. Aunque la gran mayoría de las primeras constituciones fueron sancionadas por legislaturas ordinarias (o en algún caso por una asamblea irregular que ejercía funciones legislativas), esto fue fruto de una necesidad práctica del proceso revolucionario, no un indicador de que se considerara apropiado que la legislatura se arrogara funciones constituyentes.

De 21 constituciones sancionadas entre 1776 y 1783, 18 fueron redactadas por la asamblea legislativa y tres por una convención especial (New Hampshire en 1778 y en 1781-1783 y Massachusetts en 1780). Sin embargo, la mayoría de las legislaturas (10 de los 18 casos) no se consideraron con poderes propios para ejercer el poder constituyente pues solicitaron autorización previa a la ciudadanía, sometieron la nueva Constitución a aprobación popular, o ambas cosas ${ }^{13}$. Por otra parte, como señala Wood ${ }^{14}$, con el tiempo fue consolidándose la idea de que así como la Constitución era superior a una ley ordinaria, su enmienda o reemplazo solo podía ser decidida por un órgano distinto y separado de legislatura y elegido por los votantes para ese solo propósito: la convención constitucional. Hacia 1787 esto era ya una teoría establecida ${ }^{15}$.

En otras palabras, los federalistas podían argumentar que el proceso de ratificación brindaría el consentimiento del pueblo porque se haría por medio de convenciones especiales electas por los votantes. Sin embargo, la elección de los delegados a esas convenciones debía hacerse por medio de una convocatoria realizada por las autoridades constituidas y en la que participarían todos aquellos habilitados por la ley para votar. Todos estos recaudos, hacían del mecanismo de convenciones un instrumento extraconstitucional pero tampoco abiertamente contrario a la institucionalidad vigente ${ }^{16}$. Tomando en cuenta estos antecedentes, hubiese sido posible y quizás esperable que la nueva Constitución encauzara legalmente la participación ciudadana en cambios constitucionales futuros. La experiencia exitosa de transformación constitucional en 1787 presentaba la oportunidad de transformar el poder constituyente del pueblo, de potestad prelegal de contornos difusos, en un derecho de participación ciudadana regulado constitucionalmente. Sin embargo, y a diferencia algunas constituciones estatales, la Constitución federal consagró la idea de que el poder constituyente del pueblo debía permanecer como un poder fáctico.

\section{DEL PODER CONSTITUYENTE DEL PUEBLO AL PODER REVISOR DE LOS ÓRGANOS CONSTITUIDOS}

El artículo V de la Constitución propuesta por los federalistas permitió alteraciones a la Constitución por medio de dos mecanismos alternativos: enmiendas propuestas por

\footnotetext{
13 HoAr (1917) p. 4-7. Ver también Fritz (1997: 326), quien señala que la mayoría de las legislaturas estatales que crearon constituciones entre 1776 y 1780 lo hicieron después de elecciones en la que los votantes dieron autorización a las tareas constituyentes que se les encargarían.

14 Wood (1969) pp. 306-343.

15 Ver también Jefferson, Notes on the State of Virginia (p. 250), y EF \# 22, pp. 183-184.

16 De esta ambigüedad surge la disputa acerca de si el proceso que llevó a la sanción de la Constitución de Filadelfia fue legal o ilegal. Sobre este debate, ver Amar (1995) pp. 92-103; ACKerman y Katyal, op. cit. Nota 9; KAY $(1987,2010)$.
} 
dos terceras partes de cada una de las cámaras del Congreso federal, o bien enmiendas propuestas por una convención convocada por las legislaturas de las dos terceras partes de los estados. En ambos casos, las enmiendas debían ser ratificadas ya sea por las legislaturas o convenciones electas en tres cuartas partes de los estados, según lo proponga el Congreso federal. Este artículo menciona solo enmiendas a la Constitución, sin hacer referencia al posible reemplazo de la misma. Por otro lado, si bien se considera la posibilidad de reunir una convención federal, su convocatoria queda en manos de las legislaturas locales y el modo de ratificación queda a opción del Congreso federal.

Como señala Vile ${ }^{17}$, en tanto en la convención de Filadelfia el principal debate se centró en si los estados o la legislatura federal deberían ser los órganos encargados de proponer enmiendas, durante el proceso de ratificación la disputa fue en torno al grado de dificultad que entrañaba el proceso de reforma. A pesar de las críticas que algunos antifederalistas formularon en esa dirección, no tuvo un lugar prominente en el debate público el hecho de que la nueva Constitución colocaba el poder de revisión constitucional exclusivamente en manos de los poderes constituidos ${ }^{18}$.

Podría pensarse que la razón por la cual ni el artículo $\mathrm{V}$ ni ninguna otra disposición menciona explícitamente la posibilidad de involucrar a la ciudadanía en la alteración o reemplazo de la Constitución es que se daba por sentado que esta participación sería requerida, sino de manera formal, sí informalmente por parte de los poderes constituidos en momentos de cambio constitucional ${ }^{19}$. Sin embargo, la lectura de los escritos federalistas en su conjunto deja entrever que la razón profunda de regular solo un proceso de enmienda por parte de los poderes constituidos federales o locales era parte de un proyecto de gobierno en donde luego del momento constituyente inicial era preciso relegar al pueblo de manera permanente a un papel marginal en materia de cambios constitucionales.

Thomas Jefferson fue uno de los primeros en proponer que toda vez que la Constitución debe ser revisada, es necesario encargar esa tarea a un órgano distinto de la legislatura ordinaria y dotado de un mandato expreso para alterar la Constitución. En este sentido, Jefferson propuso en su proyecto de Constitución para el estado de Virginia, de 1776, que "ninguna de estas leyes fundamentales y principios de gobierno serán rechazados o alterados sino por el consentimiento del pueblo convocado por un acto de la Legislatura a reunirse en sus respectivos condados en el mismo día; y si en esas asambleas de condado la población de dos terceras partes de los condados vota por alterar o rechazar una disposición referida por el mismo acto, dicha la alteración o rechazo pasa formar parte de la Constitución” ${ }^{20}$. En un proyecto posterior de Constitución para Virginia, del año 1783, Jefferson introduce un cambio en el mecanismo, disponiendo que "cuando dos de las tres ramas de gobierno concurran, por dos terceras partes de sus miembros, que una Convención

\footnotetext{
17 VILE (1991).

18 En tanto que algunos antifederalistas denunciaron que el artículo $\mathrm{V}$ tenía un carácter eminentemente elitista, otros argumentaron, á la Jefferson, que era necesario programar revisiones periódicas de la Constitución. Ver VILE (1991) pp. 49-50.

19 Esta pareciera ser, por ejemplo, la interpretación que propone Bruce Ackerman en los dos primeros volúmenes de su obra We the People. Ver AcKerman (1991, 1998).

20 Ver Draft of a Constitution for Virginia (1776), en JefFerson (1984) p. 345.
} 
NegretTo, Gabriel L. " "El poder constituyente en la tradición constitucional americana..."

es necesaria para alterar esta Constitución o corregir transgresiones, estarán autorizadas para llamar a la elección de delegados en cada condado" ${ }^{21}$. En ambas propuestas, Jefferson combinaba la activación del poder revisor del pueblo por medio de una convocatoria autorizada por la Legislatura, con una decisión directa de los ciudadanos reunidos en asambleas o convenciones en cada condado del estado.

Con posterioridad a estos proyectos, Jefferson elaboró lo que fue su idea más conocida acerca del poder de revisión constitucional que retiene el pueblo: que una Constitución no debiera durar más tiempo que el que dura la generación que la creó. En una carta dirigida a Madison en septiembre de 1789, Jefferson argumenta que así como la tierra pertenece en usufructo solo a los seres vivientes, la Constitución creada por una generación no debiera obligar a la siguiente. Por esta razón, Jefferson concluye que (de acuerdo a las tablas de mortalidad de la época), "toda Constitución, entonces, y toda ley, expira naturalmente al cabo de 19 años. Si se implementa por más tiempo, es un acto de fuerza, no de derecho"22. Varios años después, en 1816, Jefferson propone una variación de la misma idea, argumentando en una carta a Samuel Kercheval acerca de la reforma de la Constitución de Virginia, que es preciso que la Constitución contenga previsiones para su revisión programada cada 19 años $^{23}$.

Los mecanismos de revisión propuestos por Jefferson para la Constitución de Virginia en 1776 y 1783 no implicaban una idea enteramente original. Como lo he señalado, la convocatoria a una convención popular para revisar la Constitución se terminó convirtiendo en un principio ampliamente compartido por el constitucionalismo americano luego de la independencia. Ese principio tuvo una aceptación restringida en la Constitución federal, pues el llamado a una convención se incorporó como mecanismo excepcional en el que no queda claro el papel que tendría la participación ciudadana. En las constituciones estatales, en cambio, el mecanismo de reforma por convención tuvo una amplia aceptación. Con el tiempo, la mayoría de las constituciones estatales incluyeron una cláusula explícita para que la legislatura pudiera convocar a una convención, en muchos casos por mayoría simple. Más aún, en la mayor parte de los casos, las constituciones estatales establecieron que el llamado a convención debe ser aprobado por los votantes y que las propuestas de reforma de la convención deben ser también ratificadas por los ciudadanos ${ }^{24}$.

La idea de que la vigencia de la Constitución estuviese sujeta a un plazo fijo de expiración fue una idea más innovadora, que no fue adoptada como tal ni por la Constitución federal ni por las constituciones estatales. Sin embargo, varias constituciones locales incorporaron un mecanismo de revisión claramente jeffersoniano en espíritu: consultar a la ciudadanía cada cierto número de años si está de acuerdo con mantener la Constitución vigente o si prefiere elegir una convención para decidir cambios a la misma. Tres estados (Kentucky, Massachusetts y New Hampshire) tenían estas disposiciones a fines del siglo

\footnotetext{
21 Ver Draft of a Constitution for Virginia (1783) en http://founders.archives.gov/documents/Jefferson/01-06-02-0255-0004

22 Ver, Carta a Madison, 6 de septiembre de 1789, en Jefferson (1984) p. 963.

23 Ver Carta a Samuel Kercheval, en JefFerson (1984) p. 1402.

24 Dinan (2009) p. 31.
} 
XVIII y hoy son catorce las constituciones estatales que prevén este tipo de referendos ${ }^{25}$. También afín a las ideas de Jefferson fue la incorporación en varias constituciones (particularmente entre 1890 y 1920) del derecho ciudadano de proponer enmiendas constitucionales para ser votadas popularmente o bien proponer que se convoque una convención constitucional. Tanto este derecho de iniciativa como la consulta popular por períodos fijos a la ciudadanía permite la aprobación de cambios constitucionales aun cuando estos no fueran queridos por los legisladores.

La razón por la cual las ideas de Jefferson nunca tuvieron cabida en la Constitución federal es porque la filosofía que se incorporó a esta última fue adversa a que el poder de revisión constitucional permaneciera en manos del pueblo. Madison expone con claridad esta filosofía en el Federalista \# 49, en ocasión de discutir la propuesta de Jefferson de que dos de las tres ramas de gobierno tengan capacidad de convocar a una convención electa por el pueblo para alterar la Constitución o corregir transgresiones a la misma ${ }^{26}$. Si bien este escrito trata exclusivamente el uso de convenciones para corregir transgresiones a la Constitución, es claro que revela un rechazo general a la idea de regular la intervención organizada de la ciudadanía para evaluar la necesidad de adaptación de la Constitución.

Al comentar la propuesta de Jefferson, Madison admite que "si el pueblo es la única fuente legítima de poder, y es del mismo de donde se deriva la Constitución, bajo la cual las distintas ramas de gobierno ejercen el poder, pareciera ser estrictamente consistente con la teoría republicana recurrir a la misma fuente original de autoridad, no solo cuando sea necesario agrandar, disminuir o crear nuevos poderes de gobierno, sino también cuando cualquiera de los poderes invada la esfera de autoridad de los otros"27. Más aún, Madison reconoce que este razonamiento tiene gran fuerza y prueba "la necesidad de trazar y de mantener abierto un camino para que la decisión del pueblo se exprese en ciertas grandes y extraordinarias ocasiones" 28 . Sin embargo, por razones prácticas considera inconveniente que se pueda recurrir al pueblo por medio de un mecanismo regulado para mantener la vigencia de la Constitución.

Los argumentos principales son $\operatorname{dos}^{29}$. El primero es que "como toda apelación al pueblo llevaría implícita la existencia en el gobierno de algún defecto, la frecuencia de estos llamados privaría al gobierno, en gran parte, de esa veneración que el tiempo presta a todas las cosas y sin la cual ni los gobiernos más sabios y libres poseerían nunca la estabilidad necesaria" ${ }^{30}$. El segundo es que resulta peligroso agitar las pasiones públicas refiriendo al pueblo en forma frecuente cuestiones constitucionales. A juicio de Madison, el éxito que tuvieron los americanos en estos experimentos hasta el momento se debió a condiciones excepcionales, que podrían no repetirse en el futuro, tales como la situación de peligro

\footnotetext{
25 Dinan (2009) pp. 45-46.

26 Propuesta que Madison atribuye erróneamente a las Notas Sobre el Estado de Virginia que escribió Jefferson, pero que está contenida, como vimos, en su proyecto de Constitución para Virginia de 1783.

27 El Federalista (1987) p. 313.

28 El Federalista (1987) p. 313.

29 Otras objeciones de carácter secundario se refieren de manera particular a las dificultades e inconvenientes que presenta el mecanismo de convocar una convención por medio de dos de los tres poderes.

30 El Federalista (1987) pp. 313-314.
} 
NegretTo, Gabriel L. — "El poder constituyente en la tradición constitucional americana..."

que reprimió el espíritu de discordia e incrementó la confianza del pueblo en sus líderes ${ }^{31}$. Es obvio que estas son objeciones a la apelación frecuente al pueblo, no solo para decidir en caso de conflictos entre ramas de gobierno (el tema específico del ensayo) sino también para decidir de forma general sobre cualquier materia constitucional.

Consistente con la idea de que no es conveniente establecer canales institucionales por medio de los cuales se pueda activar con frecuencia el poder constituyente, Madison también se opuso a la idea de Jefferson de que una Constitución no debiera ser válida más allá de una generación. En su respuesta a la carta que le enviara Jefferson sobre el tema, Madison argumenta que aunque la propuesta sea válida en teoría, en la práctica se enfrenta a fuertes objeciones. Y la principal objeción es que una Constitución que se revise en forma frecuente sería demasiado mutable para retener aquellos prejuicios en su favor que inspira la antigüedad ${ }^{32}$. En contra de la idea de que el consentimiento expreso de cada generación es preciso para mantener la validez de una Constitución, Madison argumenta que solo la doctrina del consentimiento tácito, inferido de la falta de disenso, es lo que permite la durabilidad de una Constitución ${ }^{33}$.

En suma, luego del acto fundacional que le dio validez a la Constitución, el modelo de gobierno constitucional propuesto por los escritos federalistas busca hacer innecesario acudir al pueblo frecuentemente para decidir sobre la vigencia e interpretación de la Constitución. Esta tarea debe quedar en manos de los representantes reunidos en el Congreso por medio de la utilización del artículo $\mathrm{V}$ y eventualmente de los miembros del poder judicial, a través del proceso de revisión constitucional. El derecho del pueblo de alterar o abolir la Constitución se siguió considerando un principio central del constitucionalismo americano. Más aún, el mismo James Madison propuso incluir como primera enmienda de la Constitución una cláusula diciendo que todo poder deriva del pueblo y que "el pueblo tiene el derecho indudable, inalienable e irrevocable de reformar o cambiar su gobierno, cuando este sea contrario o inadecuado para los propósitos que se instituyó" 34 . Pero la clave para interpretar este "derecho" se encuentra en que solo podría ejercerse, de hecho y como última instancia, contra un gobierno opresivo; no como un recurso regular y legal en el contexto de un gobierno republicano ${ }^{35}$.

Esta visión acerca de la participación popular en materia de cambios constitucionales fue perfectamente consistente con la idea de república que promovieron los federalistas. En El Federalista \# $39^{36}$ Madison define a la república como "un gobierno que deriva todos

\footnotetext{
31 El Federalista (1987) p. 314.

32 Ver Madison (1999) p. 474.

33 Op. cit, p. 476. Un giro interesante en la argumentación que propone Madison es que si no se adoptara la doctrina del consentimiento tácito y se requiriese el consentimiento expreso de cada generación, no se tendría que aplicar la regla de la mayoría sino la de unanimidad, lo cual paralizaría la sociedad.

34 Ver Fritz (1997) pp. 317-318, nota 107.

35 En verdad, en un gobierno republicano nunca se agotarían los medios para buscar el cambio constitucional por las vías legales establecidas. Por ejemplo, si bajo las reglas del artículo V, el Congreso federal o las legislaturas estatales en un determinado momento rechazaran una reforma que reclama una mayoría ciudadana, siempre existiría la oportunidad en las próximas elecciones de votar por legisladores favorables al cambio.
}

36 El Federalista \# 39 (1987) p. 255. 
sus poderes directa o indirectamente del cuerpo ciudadano, y es administrado por personas que ejercen sus funciones por un tiempo limitado, o mientras dure su buena conducta". En esta forma de gobierno, la elección regular de representantes evitaría que las minorías dominen a las mayorías. El problema central era impedir que el gobierno republicano termine siendo controlado por una facción mayoritaria. Dos mecanismos lograrían este objetivo ${ }^{37}$. El primero sería el arreglo federal que en un territorio extenso ayudaría a acentuar las diferencias de intereses entre las poblaciones y las mayorías de los distintos estados. El segundo sería el modelo de frenos y contrapesos, la ingeniería institucional destinada a limitar el poder de la asamblea legislativa, que según Madison era la institución que estaría en contacto más directo con las mayorías nacionales.

El sistema de vetos mutuos y la diversidad de los intereses políticos representados en cada rama del poder impedirían que un agente del pueblo (en especial la legislatura) pudiera reclamar la representación unitaria de la ciudadanía y así invadir otras ramas de gobierno. La Constitución no requeriría de esta manera de ningún "guardián" de la Constitución, pues sería un sistema autorregulado de límites al poder estatal ${ }^{38}$. Es por ello también que en casos de violación a la Constitución no sería necesario llamar a convenciones populares que decidieran sobre la transgresión. Las transgresiones, en todo caso, serían mejor dirimidas por parte de una Corte Suprema, que de esta manera protegería al poder constituyente original de las desviaciones que intentaran hacer los poderes constituidos ${ }^{39}$.

La desconfianza a las mayorías, el deseo de brindar estabilidad a la Constitución, y la proposición de un esquema de equilibrio autorregulado de poderes que contuviera las tendencias expansivas de la legislatura, descartaron como opción que la ciudadanía participara por medio de canales legales en la propuesta de cambios constitucionales o que se apelara al pueblo frecuentemente para revisar la Constitución o corregir transgresiones. Si la legislatura federal pudiese convocar directamente a convenciones especiales o aprobar cambios por medio de referendos ratificatorios, esto derivaría, siguiendo la lógica de Madison, en un muy probable agrandamiento de las facultades del legislativo a expensas de las otras ramas de gobierno. Por otra parte, un mecanismo de consulta periódica a la ciudadanía sobre materias constitucionales terminaría por restar autoridad a la Constitución.

Es por estas razones que el mecanismo de enmienda y revisión constitucional establecido en el artículo $\mathrm{V}$ de la Constitución de Filadelfia se organizó de modo tal que solo pudiese ser activado por los poderes constituidos, al mismo tiempo que ninguno de estos poderes (en particular en Congreso federal) pudiese monopolizar el proceso. Sin embargo, y a pesar del éxito que tuvo el proyecto de Madison a nivel federal en cuanto al objetivo de producir estabilidad constitucional, no está claro que la regulación legal que incorporó a la Constitución pudiera cerrar para siempre el camino a formas más participativas y no previstas de cambio constitucional.

\footnotetext{
37 El primer mecanismo está descrito en EF \# 10, el segundo en los Escritos Federalistas \# 47 a 51.

38 Ver Manin (1997).

39 Sobre este punto, ver el EF \# 78 de Hamilton.
} 


\section{EL CARÁCTER NO EXCLUSIVO DEL PROCEDIMIENTO DE ENMIENDA}

En un sentido obvio, el procedimiento de enmienda de una Constitución no es el canal exclusivo por medio del cual esta puede cambiar. Las constituciones también se transforman sin necesidad de alterar sus textos, por medio de las interpretaciones que de sus normas hacen las cortes constitucionales y los poderes políticos ${ }^{40}$. Esta visión del cambio constitucional, sobre todo en lo que respecta a la interpretación judicial, no contradice el modelo de los federalistas. Más aún, como argumenta Vile ${ }^{41}$, existe una perfecta continuidad entre la intención de hacer difícil el cambio textual de la Constitución por medio de enmiendas aprobadas por el Congreso, evitar una apelación frecuente al pueblo para decidir cuestiones constitucionales, y delegar a los jueces la facultad de transformar la Constitución por vía interpretativa. Sin embargo, existe un entendimiento alternativo acerca del carácter no exclusivo del procedimiento de enmienda que sí contradice de manera abierta la teoría de los escritos federalistas. Este se refiere a la posibilidad de incorporar cambios formales a la Constitución por medio de la participación directa de los ciudadanos o de una apelación al pueblo hecha por los poderes constituidos fuera de los canales legales establecidos.

Hoy estamos acostumbrados a asociar el constitucionalismo a la idea de una Constitución rígida y la rigidez de la Constitución a un procedimiento por el cual la legislatura solo puede aprobar enmiendas mediante una votación más exigente que la que se requiere para aprobar una ley ordinaria. Estos procedimientos más demandantes refieren a mayorías calificadas, votaciones sucesivas por mayoría pero mediando una elección antes de su aprobación final, intervención de distintas cámaras o instancias institucionales, ratificación por asambleas locales, etc. Sin embargo, si seguimos la lógica de que la validez de una Constitución emana de su aceptación por parte de los gobernados y de que la Constitución establece un conjunto de pautas sobre el ejercicio del poder que no pueden ser violadas por los poderes constituidos, resulta entonces que el procedimiento de enmienda podría ser por un lado más y por otro menos restrictivo de lo que parece.

Si la validez de la Constitución emana del consentimiento del pueblo y los representantes no pueden modificar los términos de su mandato, ningún poder constituido podría legítimamente alterar aspectos fundamentales de la Constitución sin consultar a la ciudadanía. Es decir, una enmienda aprobada solamente por la legislatura que alterara decisiones fundamentales contenidas en la Constitución, como ser la forma de gobierno o la estructura del estado, no sería constitucional aunque se hubiese seguido el procedimiento establecido por la Constitución. Este es el fundamento de la llamada doctrina de las enmiendas inconstitucionales, según la cual el procedimiento de reforma no autoriza a la legislatura a cambiar aspectos de la Constitución que hacen a la estructura básica del estado, pues esta solo puede ser cambiada con el consentimiento del poder constituyente originario ${ }^{42}$.

\footnotetext{
40 Levinson, 1995; Strauss, 2001; Negretto, 2012.

41 VILE (1991) p. 52.

42 La posición clásica sobre este punto se encuentra en la distinción que hace Carl Schmitt entre Constitución y leyes constitucionales. La primera refiere a decisiones políticas fundamentales que no pueden ser alteradas por los poderes constituidos ni siquiera valiéndose del procedimiento de enmienda. Las segundas son reglas proce-
} 
Por otra parte, el procedimiento de enmienda podría ser menos restrictivo de lo que parece si se piensa que el mismo busca limitar a los poderes constituidos mas no al poder constituyente. Si la validez de la Constitución emana del pueblo y este mantiene el derecho de alterarla o suprimirla cuando lo considere conveniente, entonces el proceso de enmienda podría estar diseñado solo para impedir que la legislatura pueda alterar los términos de su delegación de la misma manera en que sanciona o reforma una ley ordinaria. Pero existirían otros mecanismos si la iniciativa o la ratificación de cambios constitucionales son realizados en forma directa por la ciudadanía. Este es el argumento central de Akhil Amar ${ }^{43}$, quien propone que las reglas de mayoría calificada que normalmente se establecen en los procedimientos de enmienda, aplican para los gobernantes y no para los gobernados, quienes podrían utilizar métodos alternativos de tipo mayoritario para alterar, revisar, o reemplazar la Constitución.

Según Amar, el principio de soberanía popular en el que se fundó la Constitución de 1787 y que se incorporó en varias cláusulas de la Constitución, lleva a interpretar el procedimiento del artículo $\mathrm{V}$ como un mecanismo que rige solo cuando actúa la legislatura en ausencia de una participación ciudadana directa. En esta perspectiva, el proceso de reforma no excluye, por ejemplo, que los ciudadanos puedan peticionar al Congreso federal convocar una convención para revisar la Constitución ${ }^{44}$. Por las mismas razones, en el caso de que los cambios fueran propuestos por el Congreso federal o por una convención, no sería forzoso que la ratificación requiriese del acuerdo de tres cuartas partes de las legislaturas locales o de convenciones estaduales. Tanto el Congreso federal como una convención podría proponer alteraciones para que las mismas sean aprobadas por mayoría simple en un referendo nacional ${ }^{45}$.

Lo interesante -y controvertido- del argumento de Amar es que este tipo de acciones no implican a su juicio un ejercicio revolucionario y extraconstitucional del poder constituyente, sino que son perfectamente legales. Según Amar, si bien la convención de Filadelfia se apartó de la interpretación literal del artículo XIII de los Artículos de la Confederación y cambió el procedimiento de ratificación por razones de necesidad y conveniencia, no se debe catalogar su estrategia como ilegal. A su juicio, la acción de la convención y sus líderes tenía fundamento en una corriente constitucional que se fue consolidando en las 13 colonias durante la década posterior a la revolución. Esta corriente habría convertido el derecho natural y revolucionario del pueblo de abolir o alterar su gobierno en un derecho legal que podía ejercerse aunque la Constitución no lo reconozca de manera explícita ${ }^{46}$.

Por esta razón, e invocando esa tradición, Amar considera que lo que ocurrió en 1787, podría volver a ocurrir si bajo condiciones similares se llamara a una convención

dimentales o regulaciones no esenciales sobre la forma de estado y de gobierno, que los poderes constituidos pueden alterar por medio del procedimiento de enmienda. Ver Schmitt (1982). Para el debate contemporáneo sobre el tema, ver Jacobsohn (2006).

43 Akhil Amar (1988) (1994).

44 En estos casos, según Amar, el Congreso estaría obligado a aceptar dicha petición si esta reúne el apoyo de una mayoría de los votantes registrados. Ver Amar (1988) p. 1065.

45 AMAR (1988), (1994) p. 457.

46 AMAR (1994) pp. 463-464. 
consultando directamente al pueblo o si una convención alterara el mecanismo de ratificación establecido en el artículo V. Por otra parte, Amar considera que la interpretación revolucionaria del derecho del pueblo a darse o cambiar su Constitución fue implícitamente incorporada al texto de la Constitución federal en todas las instancias en que la misma hace referencia al principio de soberanía popular ${ }^{47}$.

La argumentación de Amar tiene varios problemas. El más serio refiere a los fundamentos históricos que utiliza al sostener que al sancionarse la Constitución federal el pueblo habría retenido el derecho legal de cambiar la Constitución cuando lo considere conveniente y sin observar los procedimientos establecidos ${ }^{48}$. Es cierto que una interpretación radical que tuvo vigencia en muchos estados consideró el derecho del pueblo de alterar o abolir la Constitución como una prerrogativa colectiva distinta al derecho a la revolución, y que podía ejercerse aun si la Constitución guardaba silencio al respecto. Esto explica porque la mayoría de las primeras constituciones estatales no creyeron necesario establecer procedimientos de revisión y por qué muchas de ellas fueron posteriormente alteradas o reemplazadas en ausencia de regulación, o incluso en contra de las reglas establecidas. Sin embargo, no es correcto invocar esta tradición en el caso de la Constitución federal.

Como argumenté en la sección anterior, si bien es cierto que los federalistas apelaron a la tradición revolucionaria del poder constituyente del pueblo para justificar el actuar de la convención de Filadelfia, la Constitución que surgió de esta convención buscó apartarse de ese precedente. Este alejamiento puede observarse, como lo señalan algunos historiadores y juristas, en la distinta evolución que tuvo el constitucionalismo estatal y federal. Mientras que el primero buscó hacer más flexible los procedimientos de enmienda, dar mayor participación a la ciudadanía y restringir el poder de los legisladores y los jueces en materia de cambio constitucional, el segundo se mantuvo atado a un esquema elitista en donde el poder revisor quedaría en manos de estos últimos ${ }^{49}$.

Por otra parte, si bien la tradición constitucional revolucionaria se mantuvo viva en el constitucionalismo estatal bastante tiempo después de la sanción de la Constitución federal, la misma fue también abandonada hacia mitad del siglo XIX. Luego de una revisión exhaustiva de los antecedentes históricos, legales y jurisprudenciales de la convocatoria a convenciones especiales en los estados, el jurista Roger Sherman Hoar concluye que si bien una convención puede ser legal aun cuando la Constitución no prevé el mecanismo o incluso lo prohíbe, es preciso que la misma haya sido "convocada por el pueblo expresándose por medio del electorado en una elección regular" 50 . De otra manera, dicha convención sería facciosa e ilegal y sus decisiones solo podrían reconocerse si las mismas lograran imponerse por la fuerza. En otras palabras, tendría que triunfar una revolución.

Esta fue justamente la suerte de la llamada "convención del pueblo" que Thomas Dorr quiso organizar en el estado de Rhode Island entre 1841 y 1842 en ausencia de au-

\footnotetext{
47 Este sería el caso del preámbulo y las enmiendas primera, novena y décima. Ver AmAr (1994) p. 489-494.

48 Esta idea puede ser también criticada, por supuesto, desde un punto de vista puramente lógico, pues es incoherente que la Constitución presuponga un derecho legal y no explícitamente regulado para alterar o abolir la propia legalidad que la Constitución establece. Sobre este punto, ver SuBER (1990).

49 Ver Fritz (1997); Dinan (2009).

50 HOAR (1917) p. 52.
} 
torización constitucional y ante la oposición de la legislatura. La Constitución sancionada por esa convención nunca fue aceptada como legal a pesar de que esta última fue elegida popularmente y una mayoría de los hombres adultos del estado votaron a favor de la nueva Constitución ${ }^{51}$. La razón es que dicha convención fue considerada revolucionaria y al fracasar la rebelión popular de Dorr, también fracasó la Constitución que dicha rebelión apoyaba. En dicha ocasión, el gobierno federal se opuso a considerar legal la Constitución popular y su posición fue implícitamente validada por la Corte Suprema en el caso Luther vs Borden, de $1849^{52}$. Consciente de este precedente, los ejemplos que brinda Amar acerca de cómo la Constitución podría ser alterada por medio de una apelación al pueblo fuera del artículo V, siempre suponen que el Congreso federal acepta una iniciativa popular o bien consulta directamente al pueblo con el acuerdo implícito o explícito de los demás poderes. Pero como señala Vile ${ }^{53}$, si el derecho del pueblo de cambiar la Constitución en violación a los procedimientos establecidos fuera un derecho legal, entonces se debería poder ejercer incluso ante la oposición del Congreso o de otros poderes.

En suma, Amar fracasa en convencernos que el constitucionalismo americano le reconoce al pueblo el derecho legal de alterar o abolir la Constitución más allá de los procedimientos establecidos. No obstante, sus argumentos tienen el valor de llamar la atención sobre el hecho de que un intento de hacer cambios constitucionales apelando al poder constituyente al margen del artículo $\mathrm{V}$ podría encontrar reconocimiento no solo en la tradición revolucionaria sino en los fundamentos últimos de la Constitución. Esto no ha ocurrido en los Estados Unidos a nivel federal, pero eso no quiere decir que no pudiera ocurrir en una situación de crisis, donde ante la urgencia de realizar ciertos cambios demandados por la ciudadanía, los poderes constituidos acepten un cambio extralegal. En otras palabras, si bien el derecho del pueblo no sería considerado legal, tampoco quiere decir que no habría argumentos para aceptar la legitimidad democrática de esos cambios. Como veremos, la posibilidad de usar esta argumentación es aún mayor en países donde la estabilidad constitucional y el respeto a legalidad es más frágil que en los Estados Unidos.

Los argumentos de Amar tienen varios puntos de conexión con la teoría de Bruce Ackerman acerca del cambio constitucional. Este último coincide con Amar en la idea de que el artículo $\mathrm{V}$ de la Constitución americana no es el único camino para introducir cambios a la Constitución ${ }^{54}$. En su visión, los federalistas establecieron una Constitución dualista que contiene dos mecanismos superpuestos de legislación, uno ordinario y otro extraordinario. El primero es el proceso legislativo normal que controlan los representantes y los partidos políticos, quienes tienen autoridad para tomar decisiones de política pública pero no para introducir cambios (formales o informales) a la Constitución que el pueblo sancionó. El segundo mecanismo es un proceso más demandante en el que los representantes obtienen autoridad para cambiar las decisiones constitucionales del pueblo solo luego

\footnotetext{
51 Sobre la rebelión de Thomas Dorr y las discusiones acerca de la legalidad de la convención del pueblo de Rhode Island, ver Thompson (2001).

52 Ver Vile (1991) p. 53.

53 Vile (1993) pp. 101-102.

54 Ackerman (1995) p. 72.
} 
de movilizar a un gran número de ciudadanos y obtener su apoyo sostenido en el tiempo ${ }^{55}$. Según Ackerman, este proceso de movilización implica un gran debate constitucional nacional que comienza con una serie de conflictos entre ramas de gobierno acerca del contenido y sentido del cambio y culmina en una secuencia de victorias electorales en las que una visión triunfa sobre otra superando los vetos institucionales a su implementación ${ }^{56}$. Solo una vez que esto ocurre puede considerarse que el pueblo (con mayúsculas) "ha hablado", de modo tal que ya no se trata de una decisión de un grupo de representantes sino que refleja el juicio considerado de una amplia mayoría de ciudadanos.

El trabajo de Ackerman presta en general poca atención a los detalles institucionales de las reglas para implementar cambios constitucionales al margen del artículo $\mathrm{V}$ y, a diferencia de Amar, no considera que la convocatoria de convenciones populares tenga que ocupar un lugar privilegiado como ruta alternativa de transformación constitucional. En su visión, las convenciones especiales son un antecedente válido en la tradición constitucional americana del siglo XVIII, pero el período de la Reconstrucción y el New Deal brindan precedentes igualmente importantes. Estos precedentes señalan que es el reiterado apoyo de una propuesta de cambio por parte de los votantes en sucesivas elecciones lo que permite descubrir la existencia de una auténtica voluntad popular a favor de un cambio determinado. Dada esta condición, es posible que algunos cambios se realicen utilizando la forma, aunque no necesariamente respetando el espíritu del artículo $\mathrm{V}$, mientras que en otros casos se recurra a interpretaciones innovadoras y transformadoras de la justicia.

Sin embargo, Ackerman reconoce que el uso de vías de cambio constitucional distintas a la establecida en el artículo $\mathrm{V}$ puede prestarse al abuso, particularmente por parte de Presidentes que sin contar con un auténtico mandato popular (como, a su juicio, lo tenía Roosevelt) utilizan nombramientos en la justicia para realizar cambios interpretativos a la Constitución. Al mismo tiempo, tampoco es una solución aferrarse al artículo $\mathrm{V}$ ante estos abusos, pues este tampoco asegura que las enmiendas gocen de un auténtico respaldo popular. Ante esta situación, Ackerman propone un procedimiento según el cual el Presidente en su segundo mandato puede proponer enmiendas al Congreso, para que en caso de ser aprobadas por este último por dos terceras partes de ambas cámaras, se sometan durante las próximas dos elecciones al voto popular. Si tres quintas partes de los votantes que participan en estas elecciones aprueban la enmienda, esta quedaría ratificada en nombre del pueblo de los Estados Unidos ${ }^{57}$. Si bien en su formulación inicial Ackerman propone incorporar este procedimiento como reforma al artículo V, no aclara si el mismo se convertiría en un nuevo y único procedimiento de enmienda que sustituiría al anterior, o si se utilizaría como mecanismo alternativo.

Hacia el final del segundo volumen de We the People, Ackerman vuelve a retomar esta propuesta, a la que llama ahora "iniciativa de soberanía popular" ${ }^{58}$. La principal diferencia con la propuesta inicial refiere a cómo podría adoptarse el nuevo método de enmien-

\footnotetext{
55 ACKERMAN (1991) pp. 6-7.

56 ACKerman (1998) p. 20.

57 ACKerman (1991) pp. 54-55.

58 ACKerman (1998) pp. 410-412.
} 
das ${ }^{59}$. Si este procedimiento es incorporado a la Constitución por medio de una enmienda al artículo V, como Ackerman parecía sugerir en su primer análisis, seguramente no sería aprobado por los estados, pues lógicamente no aceptarían renunciar a su control sobre futuras reformas. Por esta razón, propone que la iniciativa de soberanía popular debiera implementarse por medio de una ley especial, sometida por el Presidente para la aprobación de dos terceras partes del Congreso ${ }^{60}$. En su consideración final, entonces, Ackerman estaría proponiendo un procedimiento de enmienda paralelo al artículo $\mathrm{V}$ y fuera del mismo. Si bien esto seguiría los precedentes históricos de realizar enmiendas al margen del artículo $\mathrm{V}$, su ejecución por medio de una ley especial haría que la misma pudiera ser cuestionada constitucionalmente ante la justicia. Esto es irónico, sin embargo, pues la iniciativa de soberanía popular justamente busca limitar la intervención de los jueces en cambios constitucionales.

Otros autores de gran peso en la teoría constitucional americana, como Sanford Levinson, partiendo también de la idea de que el artículo $\mathrm{V}$ no permite una expresión directa de la ciudadanía y es muy costoso y casi imposible de implementar, sugieren que existen formas creativas de evadir sus límites. En este espíritu, Levinson sugiere que sería válido organizar una campaña nacional de petición ante los miembros del Congreso para que este último vote por la convocatoria de una convención constituyente que decida sobre la necesidad de hacer cambios a la Constitución ${ }^{61}$.

A diferencia de Amar, Levinson no discute sobre si el Congreso federal debiera estar obligado a aceptar dicha petición y más bien cree que sería facultativo. Esto implica que en caso de negativa del Congreso, sería preciso seguir el curso del artículo $\mathrm{V}$ en cuanto a la petición a través de dos terceras partes de las legislaturas estatales. Levinson menciona también un referendo nacional convocado por el Congreso pidiendo al electorado nacional que apruebe o rechace la moción de llamar a una convención para elaborar una nueva Constitución, pero no dice si tal tipo de referendo podría justificarse en términos legales y prefiere mantenerlo como un mero ejercicio mental. Lo que sí sugiere, en cambio, es la posibilidad de realizar un referendo informal por medio de asambleas de ciudadanos que de estar a favor de una nueva convención, pondrían presión al Congreso para tomar seriamente la propuesta $^{62}$.

El problema fundamental de todos estos análisis es que no cuestionan a fondo los peligros que entraña la idea de cambiar la Constitución por medio de mecanismos alternativos a los establecidos en el texto vigente. Se asume una feliz concurrencia de voluntades entre las mayorías populares y los distintos poderes constituidos y no se consideran a fondo las alternativas que se abren cuando Presidente y Congreso difieren en cuanto a la necesidad del cambio o cuando una corte constitucional decide en contra de la constitucionalidad del procedimiento. Por otra parte, cuando se hacen propuestas de reforma, no

\footnotetext{
59 Una variante menor, pero referida al contenido del nuevo mecanismo es que Ackerman no insiste ahora en que los votantes deberán ratificar las enmiendas por una mayoría calificada.

60 ACKerman (1998) p. 415.

61 LeVinson (2006) p. 173.

62 LeVinson (2006) p. 179.
} 
pareciera tomarse muy en serio la necesidad de discutir con precisión cuáles debieran ser los nuevos mecanismos, no solo a la luz de principios abstractos de legitimidad democrática basados en la voluntad de mayorías nacionales sino también previendo la posibilidad de que esta voluntad sea usurpada por alguno de los poderes constituidos.

\section{LA NECESIDAD DE INSTITUCIONALIZAR LA PARTICIPACIÓN CIUDADANA EN REVISIONES CONSTITUCIONALES}

La discusión precedente no es un mero análisis histórico acerca de la evolución del constitucionalismo americano. Por el contrario, refiere al origen de un tema de gran relevancia para los debates contemporáneos acerca de la relación entre constitucionalismo y democracia. La teoría de revisión constitucional que postularon los federalistas se tornó predominante en el mundo jurídico y el tipo de procedimiento de reforma que adoptó la Constitución americana se trasladó a la mayor parte de las constituciones del mundo. De esta manera, tanto en la teoría constitucional como en las constituciones efectivamente vigentes se relegó el poder constituyente del pueblo a un mítico acto fundacional que solo podría ser ejercido nuevamente de manera extralegal. Esta situación ha generado y genera innumerables problemas toda vez que en un régimen democrático se cuestiona la continuidad de la Constitución y se busca reemplazarla de manera pacífica.

La teoría del poder constituyente popular, como poder anterior y superior al orden jurídico establecido, fue perfeccionada durante las revoluciones americana y francesa con el objetivo de fundar una república y cuestionar la legitimidad del viejo orden monárquico. También se ha invocado la idea del pueblo constituyente durante la creación de un nuevo estado, o al transitar de un régimen autoritario a uno democrático. En estos contextos, tiene cierto sentido pensar en un poder colectivo ajeno a toda normatividad legal y fundante de la misma, puesto que la Constitución precedente no existe o bien fue creada por un orden político que perdió legitimidad y que en los hechos ha colapsado. Pero la misma idea resulta problemática en un régimen democrático donde el pueblo se conforma por el conjunto de ciudadanos que expresan su voluntad de manera periódica por medio de actos regulados legalmente. Si en ese sistema la Constitución no prevé el involucramiento de los ciudadanos en materia de cambios constitucionales, quiere decir que esa participación se activará de manera puramente fáctica y solo podrá canalizarse en forma pacífica y legal por medio de los poderes constituidos. Esta situación tiende a generar un alto grado de incertidumbre, manipulación y conflicto.

Supongamos que ante una determinada coyuntura surgiera dentro de un régimen democrático una fuerte corriente de opinión, quizás acompañada por actos de movilización ciudadana, que reclamara la creación de una nueva Constitución. La alternativa más deseable sería que la elite política acepte el reclamo, permita a la ciudadanía expresar sus preferencias de manera autónoma, y las distintas instituciones del estado regulen consensualmente el proceso. Sin embargo, puede ocurrir que tanto el gobierno como la oposición y los distintos poderes institucionales decidan cerrar u obstaculizar el camino al cambio, quizás por considerarlo riesgoso para sus intereses. También es posible que mientras uno de los poderes del estado acepte la necesidad de reemplazar la Constitución, otro la rechace. 
En su especulación sobre cambios constitucionales fuera del procedimiento de enmienda, Ackerman proponía que un Presidente popular debería estar habilitado a enviar propuestas de reforma para la aprobación de la ciudadanía previa autorización del Congreso por mayoría calificada. ¿Pero no podría un Presidente popular pasar por encima de un Congreso recalcitrante y someter las reformas a una aprobación directa de la ciudanía en nombre del poder constituyente? Es preciso notar que la posibilidad de conflicto es muy alta porque cualquier procedimiento genera costos y beneficios asimétricos para los actores involucrados, dependiendo de sus recursos presentes y expectativas futuras. Por ejemplo, mientras las legislaturas suelen oponerse a la redacción de una nueva Constitución por medio de una convención especial paralela, un Presidente popular pero con apoyo minoritario en el Congreso bien podría ver en la elección de una asamblea constituyente la posibilidad de redistribuir poder en su favor.

Un grupo reducido de constituciones en el mundo han buscado escapar a estos problemas brindando una vía legal para su reemplazo. Algunas de ellas, particularmente en el contexto de regímenes parlamentarios, permiten que la legislatura ordinaria apruebe tanto reformas parciales como totales, a veces estableciendo un procedimiento distinto para esto último $^{63}$. Sin embargo, hay dos escenarios en que esta salida podría no ofrecer una real solución. El primero es aquel en que la legislatura se opone al reemplazo de la Constitución y la ciudadanía carece de instrumentos propios, como una iniciativa popular, para impulsar el proceso. El segundo es aquel en que la legislatura favorece el cambio, pero este cuerpo no goza de legitimidad ante la opinión pública. Por otra parte, hay también algunas constituciones, particularmente en América Latina, que prevén el llamado a una convención para su reforma total o reemplazo ${ }^{64}$. Estas constituciones sí permiten una salida en el caso de que se requiera de un cuerpo constituyente especial, aunque algunas de estas fueron en su momento creadas irregularmente y, como veremos, heredaron la arbitrariedad del proceso bajo el cual se crearon.

La posibilidad de que surja una demanda ciudadana para refundar el orden constitucional se incrementa en regímenes democráticos cuyo desempeño es deficiente. Cuando los gobiernos son incapaces de proveer bienes públicos básicos y alcanzar niveles adecuados de desarrollo económico y social, la ciudadanía tiende a ser crítica de las instituciones representativas y desconfiar de la dirigencia política en general. Esta percepción compartida genera un escenario propicio para que desde distintos sectores se presenten propuestas de

63 Este es, por ejemplo, el caso de Suiza, Suecia o Finlandia, cuyas constituciones permiten que el parlamento, por medio de un procedimiento especial, pueda no solo enmendar la Constitución vigente sino también aprobar una nueva Constitución. Los parlamentos de estos países han utilizado estos poderes para sancionar nuevas constituciones en 1999, 1974 y 2000, respectivamente. En América Latina, ha sido el caso de Uruguay, que adoptó varios aspectos del proceso de enmienda de la Constitución Suiza.

64 Antes de 1978, previeron la convocatoria de una asamblea o convención constituyente en la región (en general para tratar reformas generales o ciertos artículos o principios, aunque a veces también para cualquier reforma parcial) la Constitución argentina de 1853, la de Costa Rica de 1949 (luego de la reforma de 1968), la de Guatemala de 1945, la de Honduras entre 1894 y 1936, y la de Uruguay de 1967. Actualmente regulan la convocatoria a una convención especial la Constitución argentina de 1994, la de Bolivia de 2009, la de Colombia de 1991, la de Ecuador de 2008, la de Guatemala de 1985, la de Nicaragua de 1987, la de Panamá de 1972 (luego de la reforma de 2004), la de Paraguay de 1992 y la de Venezuela de 1999. Ver Negretto $(2015,2016)$. 
reforma institucional profunda que suelen alcanzar un apoyo social extendido cuando el país atraviesa por frecuentes crisis económicas o políticas. Todas estas características se han dado en América Latina y no es casual que haya sido en las nuevas democracias de esta región donde se produjeran recientemente el mayor número de reemplazos constitucionales en el mundo ${ }^{65}$.

Como consecuencia de distintas disfuncionalidades en el desempeño de la democracia, se han reemplazado constituciones en América Latina en Colombia (1990-1991), Ecuador (1997-1998 y 2007-2008), Venezuela (1998-1999) y Bolivia (2006-2009). También es posible contar entre estos casos el de Perú, que cambió su Constitución en 1993, aunque el régimen ya había dejado de ser democrático poco antes de iniciarse el proceso. Asimismo, la discusión constituyente se ha instalado actualmente en países como Chile y Panamá, que consolidaron su régimen democrático con constituciones sancionadas en una dictadura y que con el tiempo acumularon críticas por su falta de legitimidad de origen.

El todos los casos mencionados de reemplazo constitucional, este se realizó en ausencia de una regulación previa. Ante el vacío legal, la disyuntiva inicial fue si la regulación del proceso se haría por medio de una enmienda al procedimiento de reforma de la Constitución vigente o por la creación de un procedimiento paralelo. En caso de que se decidiera por un mecanismo paralelo, el mismo podía ser establecido de varias maneras: por un acuerdo institucional entre el ejecutivo y la legislatura, un acuerdo político entre el gobierno y los principales partidos, o por decisión unilateral del ejecutivo. Las alternativas que se siguieron en cada caso jugaron un papel importante en el fortalecimiento o debilitamiento futuro de la democracia en el país.

El caso de Bolivia ejemplifica la salida más legalista, a pesar de las múltiples transgresiones que sufrió el proceso durante su implementación ${ }^{66}$. Este inició formalmente con una enmienda del año 2004 al procedimiento de reforma vigente, con el fin de autorizar a la legislatura a convocar una asamblea constituyente y regular su funcionamiento y atribuciones en casos de reforma "total" ${ }^{67}$. Con base en esta enmienda, la legislatura sancionó en 2006 una ley de convocatoria donde se especificaba el mecanismo de elección, las funciones y atribuciones de la asamblea, e incluso su procedimiento de decisión ${ }^{68}$. Un mayor grado de ruptura con la legalidad precedente lo representan los casos de Ecuador entre 1997 y 1998 y Colombia entre 1990 y $1991^{69}$.

En Ecuador el proceso comienza con una consulta popular convocada por el Presidente interino, en uso de facultades propias y con acuerdo del congreso, para que la ciu-

\footnotetext{
65 Se han creado desde 1978 relativamente pocas nuevas constituciones dentro de un régimen democrático ya establecido que cuente con más de 5 años de duración. Bajo estas condiciones, fueron adoptadas en América Latina las constituciones de Argentina (1994), Bolivia (2009), Colombia (1991), Ecuador (1998), Ecuador (2008), y Venezuela (1999). En el resto del mundo, este tipo de reemplazos solo han ocurrido en Suiza (1999), Finlandia (2000), Polonia (1997), Hungría (2011), Kenia (2010), Ucrania (1996) y Tailandia (1997).

66 Para un análisis en profundidad del caso boliviano, ver BöHrT IrAHOLA (2013).

${ }^{67}$ Hasta ese momento la Constitución solo permitía reformas parciales a la Constitución por medio de un procedimiento especial de aprobación parlamentaria.

68 Para una comparación de los casos de Bolivia, Ecuador y Venezuela, ver SÁnchez Sandoval y Welp (2013).

69 Para una comparación de estos casos, ver Negretto (2013).
} 
dadanía decida si autorizaba o no la convocatoria de una asamblea constituyente. Como resultado del apoyo popular a la asamblea, el congreso aprobó una cláusula transitoria que se añadió a la Constitución para regular la elección y funcionamiento de la misma. ${ }^{70}$ En el caso de Colombia, también se convocó una consulta popular para autorizar la elección de una asamblea constituyente, pero se lo hizo por medio de un decreto del ejecutivo, de dudosa legalidad, y sin participación del congreso $^{71}$. No obstante, una vez que la ciudadanía aprobó el llamado a la constituyente, el Presidente recién electo realizó un acuerdo con los líderes de todos los principales partidos con el fin de decidir en común los procedimientos de elección y funcionamiento de la asamblea.

Por último, tenemos los casos de Venezuela 1998-1999 y Ecuador 2007-2008, cuyas características procedimentales son en muchos aspectos semejantes al proceso constituyente que tuvo lugar en Perú entre 1992 y 1993. Estos fueron episodios no solo de ruptura legal radical sino también de falta de acuerdo entre los actores políticos e institucionales acerca de la regulación de la asamblea. Al igual que en Colombia, el proceso venezolano de 19981999 y el ecuatoriano de 2007-2008 comienza con una consulta popular convocada por el ejecutivo, de cuestionable legalidad, para decidir si se elegiría una asamblea constituyente. A diferencia de Colombia, sin embargo, ese referendo fue seguido por una decisión unilateral del gobierno acerca de la elección, atribuciones y funcionamiento de la asamblea. Como resultado, el gobierno logró que su partido pudiese controlar la asamblea, quien a su vez reclamó poderes soberanos para intervenir la legislatura y otros poderes del estado. Finalmente se sometió la nueva Constitución a un referendo como forma de subsanar las irregularidades del proceso.

Si bien la ausencia de regulación precedente creó importantes conflictos políticos y legales en todos los casos, la forma en que se implementó el proceso constituyente tuvo consecuencias distintas para la democracia. En Bolivia, Colombia y en el primer reemplazo constitucional en Ecuador, el régimen democrático se mantuvo tanto durante como después de sancionarse la nueva Constitución. En cambio, Venezuela dejó de tener una democracia en 2006 y Ecuador en $2007^{72}$. La erosión de la democracia en estos casos tuvo una vinculación estrecha con un proceso constituyente en el que el Presidente utilizó el apoyo popular a una nueva Constitución para decidir una forma de elección y de atribución de poderes a la constituyente que sirviera para cooptar todas las instituciones del Estado por parte del partido de gobierno.

Lo que estas experiencias dejan como lección es que una Constitución democrática debería permitir que la ciudadanía participe de manera efectiva y pacífica en cambios constitucionales trascendentes y al mismo tiempo impedir que una apelación al poder constituyente sea aprovechada por parte de actores políticos que buscan concentrar poder en nombre del pueblo. Para lograr estos objetivos no solo deben otorgarse instrumentos que

\footnotetext{
70 Esto significa que si bien se estableció un procedimiento paralelo al procedimiento de enmienda de la Constitución vigente, se buscó de todas maneras darle una base constitucional.

71 El gobierno de Barco invocó poderes emergentes del estado de sitio que regía en el país para convocar la consulta.

72 Ver al respecto el índice de Polity IV (2015), que es uno de los más usados en ciencia política comparada para medir los niveles anuales de democracia y autoritarismo en distintos países del mundo.
} 
NegretTo, Gabriel L. — "El poder constituyente en la tradición constitucional americana...”

permitan la participación popular por medio de peticiones y referendos sino también, y de manera crucial, crear mecanismos que respeten el principio de inclusión y diversidad en los distintos cuerpos representativos que intervienen en el proceso. Algunos de los criterios de diseño que deberían utilizarse con este fin son los siguientes:

1. Establecer una gradación de procedimientos de reforma de manera tal que conforme más profundo sea el cambio deseado, mayor sea el involucramiento de los ciudadanos en el mismo. Por ejemplo, mientras una enmienda aislada de carácter técnico podría aprobarse solo por el Congreso, una reforma parcial significativa debiera contar con una instancia de ratificación popular. Siguiendo la misma lógica, una reforma total o reemplazo de la Constitución debería contar con una autorización popular inicial, una elección especial del cuerpo colectivo encargado de aprobar el nuevo texto, y quizás un proceso de ratificación posterior. Los detalles pueden variar, pero una regulación de este tipo superaría el vacío legal en los procesos de reemplazo y limitaría la discrecionalidad de los representantes en materia de cambios constitucionales.

2. Incorporar el derecho de iniciativa popular para someter a votación reformas constitucionales o la decisión de reemplazar la Constitución. Este derecho haría posible encontrar una salida institucional toda vez que una mayoría ciudadana apoye un cambio constitucional y este sea rechazado por alguno de los poderes constituidos.

3. Autorizar a los poderes constituidos a someter reformas constitucionales o la convocatoria de un cuerpo constituyente a la votación directa de la ciudadanía siempre y cuando se obtenga un acuerdo entre el Presidente y el Congreso, el apoyo de una mayoría calificada en este último, o ambas cosas. Este mecanismo haría más difícil que un solo actor político se aproveche de mayorías circunstanciales para realizar reformas que redistribuyan poder en su favor.

4. Si se permite la convocatoria a una convención especial en casos de reemplazo o reforma total, establecer cómo se decidirán las reglas de elección de la misma, cuál sería su mecanismo de decisión y qué poderes tendría hasta que se sancione una nueva Constitución. Esta regulación es fundamental para disminuir el peligro de que una convención dominada por alguna fuerza política se declare soberana, intervenga los poderes constituidos y se convierta en instrumento para la captura del Estado.

Como lo mencioné anteriormente, algunas de las constituciones recientemente creadas en América Latina regulan la participación ciudadana en cambios constitucionales. Sin embargo, no todos esos procedimientos son igualmente aceptables desde una perspectiva normativa que busque encontrar un balance entre participación popular y pluralismo representativo. Por ejemplo, la nueva Constitución colombiana permite que el Congreso convoque una consulta popular para decidir si se elegirá una asamblea encargada de redactar una nueva Constitución. Sin embargo, no brinda a los ciudadanos la posibilidad de peticionar dicha convocatoria o someterla a referendo sin la aprobación de la legislatura. Por otra parte, las nuevas constituciones de Venezuela y Ecuador proveen de dichos instrumentos a la ciudadanía, pero también permiten que un Presidente popular pueda aprobar cambios constitucionales en su beneficio. Ambas constituciones autorizan al Presidente para 
que de manera unilateral someta a voto popular propuestas de enmienda constitucional. También le dan iniciativa parar convocar, sin consentimiento del Congreso (aunque por medio de aprobación popular en el caso de Ecuador), a una convención constituyente. Más cercana a un equilibrio entre participación popular y pluralismo representativo es la regulación que incluye la Constitución de Bolivia. Esta le permite a los ciudadanos convocar a un referendo para decidir si se reemplazará la Constitución por medio de una convención constituyente, pero contiene mayores recaudos para impedir la manipulación del proceso por parte de un grupo político. Aunque el Presidente puede pedir un referendo para decidir si se reemplaza la Constitución, no tiene la capacidad de someter unilateralmente a votación popular la aprobación de enmiendas. También establece que si bien la asamblea constituyente puede autorregularse, la misma debe aprobar la nueva Constitución por dos tercios de sus miembros presentes.

El punto central de esta discusión es mostrar que la teoría constitucional liberal, de la cual los federalistas fueron sus principales fundadores, carece de un esquema analítico adecuado para evaluar estos procedimientos, dada su negación a viabilizar legalmente la participación popular en cambios constitucionales. Curiosamente, el constitucionalismo liberal se emparenta en este punto con la teoría populista del poder constituyente, representada inicialmente por Sieyès y más tardíamente por Carl Schmitt. Según estos autores, el poder constituyente, en tanto que creador de normatividad, no tiene cabida en un sistema legal. Esta teoría confunde la atribución del poder constituyente al pueblo, que en su origen no deriva de una norma legal, con la expresión y manifestación de dicho poder, que necesariamente depende de canales institucionales que podrían ser establecidos con anterioridad a su aparición ${ }^{73}$. En lo sustancial, sin embargo, ambas posturas coinciden en relegar el ejercicio del poder constituyente a un momento excepcional y revolucionario, de necesaria ruptura con la legalidad precedente.

Sin embargo, dar vías institucionales al involucramiento de los ciudadanos en cambios constitucionales, no solo hace compatible a la Constitución con su propio principio de legitimidad sino que hace más difícil abusar de esos procedimientos por parte de los representantes y de los poderes constituidos. Esto, por supuesto, no impide su alteración futura ni tampoco los hace inmunes a un uso oportunista. No obstante, esa regulación hace necesario que se justifique públicamente la necesidad de apartarse de los procedimientos, incrementa los costos de transgredirlos, y brinda a las Cortes Constitucionales una carta de ruta para poder evaluar la constitucionalidad de un proceso de revisión que vaya más allá de la simple enmienda parcial de la Constitución.

\footnotetext{
73 Ver en este respecto, BÖCKENFÖRDE (2000) p. 169. Carl Schmitt distingue entre la activación de la voluntad constituyente del pueblo, que depende de una decisión política que no puede ser mediada ni organizada por reglas constitucionales, de la ejecución de esa voluntad, que puede ser sujeta a procedimientos. A pesar de esta distinción, sin embargo, Schmitt considera que los procedimientos bajo los cuales se ejecuta la voluntad constituyente son establecidos en base a prácticas históricas cambiantes que no corresponde reglamentar en la Constitución. Ver SсHмітт (1982) pp. 93-103.
} 


\section{CONCLUSIÓN}

El modelo de gobierno que propusieron los federalistas americanos encierra una contradicción que afecta al constitucionalismo liberal y a las democracias que se fundaron en esta tradición. La contradicción consiste en postular el principio de soberanía popular como fuente de la legitimidad y validez de la Constitución mientras que por otra parte se excluye la participación directa de la ciudanía en los procesos de revisión y reemplazo de la misma. Sin embargo, como en una democracia esta exclusión no puede abolir el derecho inalienable del pueblo de alterar o suprimir la Constitución vigente, siempre es posible invocar al poder constituyente para implementar reformas o reemplazos extralegales.

El problema es que en ausencia de una regulación legal no es posible discriminar qué procedimientos estarían incluidos o no dentro de la lógica del poder constituyente democrático, que es muy poco clara en sus implicaciones institucionales. Esto hace posible tanto que las elites políticas impidan u obstaculicen cambios constitucionales que gozan de amplio apoyo ciudadano como que un actor político realice cambios en nombre del pueblo para redistribuir poder en su favor. Esta última posibilidad aumenta en democracias presidenciales donde el titular del poder ejecutivo reclama ser el representante único de la voluntad unitaria del pueblo en un contexto de instituciones débiles e inestables. En particular, en un sistema de separación de poderes donde el Congreso y los partidos suelen tener los peores niveles de aprobación popular, el Presidente puede adquirir la capacidad de presentarse como un delegado del pueblo y organizar un cambio constitucional plebiscitario que concentre poder en sus manos y vulnere derechos individuales y colectivos. Este peligro no solo existe sino que se ha materializado recientemente en América Latina.

Una forma de atenuar este problema es apartarse de la doctrina de los federalistas y aceptar la necesidad de reconocer la participación ciudadana en los procesos de revisión y reemplazo constitucional. Este reconocimiento implica transformar la idea del poder constituyente originario, depositario de la soberanía, prelegal y sin límites, en un derecho ciudadano cuyo ejercicio requiere de regulación constitucional con el fin de hacerlo efectivo y dificultar que el mismo sea manipulado por los representantes. Como bien lo observó Madison, el pueblo solo se convierte en agente del cambio constitucional por medio de la ratificación de (o falta de oposición a) las decisiones de una minoría, inicialmente no autorizada, que actúa en su nombre. Para reducir el margen de arbitrariedad de esa minoría es preciso regular las contadas ocasiones en que dentro de un orden democrático los representantes podrían argumentar con cierta dosis de verdad que un cambio constitucional resultó aprobado por el cuerpo ciudadano.

\section{BIBLIOGRAFÍA CITADA}

Ackerman, Bruce (1991): We the People: Foundations (Cambridge, Harvard University Press). Ackerman, Bruce (1995): "Higher Lawmaking", en Sanford Levinson (edit.), Responding to Imperfection. The Theory and Practice of Constitutional Amendment (New Jersey, Princeton University Press) pp. 63-87. 
Ackerman, Bruce y Neal, Katyal (1995): "Our Unconventional Founding”, The University of Chicago Law Review, vol. 62, No 2: pp. 478-573.

Ackerman, Bruce y Neal, Katyal (1998): We the People: Transformations (Cambridge, Harvard University Press).

Amar, Akhill (1988): "Philadelphia Revisited: Amending the Constitution Outside Article V", The University of Chicago Law Review, vol. 55, No 4: pp. 1043-1104.

Amar, Akhill (1994): "The Consent of the Governed: Constitutional Amendment Outside Article V", Columbia Law Review, vol. 94: pp. 457-508.

Arato, Andrew (1995): "Forms of Constitution-Making and Theories of Democracy", Cardozo Law Review, vol. 1, No 2: pp. 191-231.

Arendt, Hannah (1963): On Revolution (New York, Penguin).

BÖCKENFÖRDE, Ernst (2000): Estudios sobre el Estado de Derecho y la democracia (Madrid, Trotta).

Böhrt Irahola (2013): "El Proceso Constituyente Boliviano", en Carlos Böhrt Irahola y Norman Wray Reyes (eds.), Los Procesos Constituyentes Boliviano y Ecuatoriano: Análisis Comparativo y Prospectiva. Stockholm: IDEA International.

Colon-Ríos, Joel (2012): Weak Constitutionalism. Democratic Legitimacy and the Question of Constituent Power (New York: Routledge).

Dinan, John (2009): The American State Constitutional Tradition (Kansas, Kansas University Press).

Frank, Jason (2007): "Unauthorized Propositions: The Federalist Papers and Constituent Power”, Diacritics, vol. 37, No2-3: pp. 103-120.

FrITZ, Christian (1997): "Alternative Visions of American Constitutionalism: Popular Sovereignty and the Early American Debate", Hatings Constitutional Law Quarterly, vol. 24, No 2: pp. 287-357.

HoAr, Roger Sherman (1917): Constitutional Conventions: Their Nature, Powers, and Limitations (Boston, Little, Brown, and Company).

Kalyvas, Andreas ( 2005): "Popular Sovereignty, Democracy, and the Constituent Power", Constellations, Vol. 12, No 2: pp. 223-244.

JaCOBSOHN, Gary F (2006) "An unconstitutional constitution? A comparative perspective", International Journal of Constitutional Law, vol. 4, No 3: pp. 460-487.

JefFerson, Thomas (1984): Writings (New York, The Library of America).

KaY, Richard s. (1987): “The Illegality of the Constitution”, Constitutional Commentary, Vol 4: pp. 57-80.

Kay, Richard s. (2010): "Constituent Authority", The American Journal of Comparative Constitutional Law, Vol 59: pp. 715-761.

Landau, David (2013): “Abusive Constitutionalism”, UC Davis Law Review, vol. 47: pp. $1-58$.

Levinson, Sanford (1995): "How Many Times Has the United States Constitution Been Amended?", en Sanford Levinson (edit.), Responding to Imperfection: The Theory and Practice of Constitutional Amendment (Princeton, NJ, Princeton University Press) pp. 13-36. 
LeVInson, Sanford (2006): Our Undemocratic Constitution (New York, Oxford University Press).

Madison, James, Hamilton, Alexander y Jay, John (1788) [1987]: The Federalist Papers (London, Penguin).

Madison, James (1999): Writings (New York, The Library of America).

Manin, Bernard (1997): "Checks, Balances, and Boundaries: the Separation of Powers in the Constitutional Debate of 1787", en Biancamaria Fontana (edit.), The Invention of the Modern Republic (New York, Cambridge University Press) pp. 27-62.

Negretto, Gabriel L (2012): "Replacing and Amending Constitutions. The Logic of Constitutional Change in Latin America”, Law \& Society Review, vol. 46, No. 4 (2012): pp. 749-779.

Negretto, Gabriel L (2015): "Procesos constituyentes y refundación democrática: el caso de Chile en perspectiva comparada", Revista de Ciencia Politica, vol. 35, No. 1.

Palmer, Robert (1970): “The People as Constituent Power”, en John R. Howe Jr. (edit.), The Role of Ideology in the American Revolution (New York, Holt, Rinehart and Winston) pp. 73-82.

Paine, Thomas (1995) [1791]: "Rights of Man", en Thomas Paine: Collected Writings (Library of America, New York).

Polity IV Project (2015): Polity IV: Regime Authority Characteristics and Transitions Datasets. Polity IV Project: Polity IV Annual Time-Series, 1800-2014.

Schmitт, Carl (1982): Teoría de la Constitución (Madrid, Alianza Universidad).

SIEYĖS, Emmanuel Joseph (2003): "What is the Third State?", en Political Writings (Cambridge, England, Hackett).

Strauss, David A (2001): “The Irrelevance of Constitutional Amendments", en 114 Harvard Law Review 1457, pp. 1457-1505.

Suber, Peter (1990): The Paradox of Self-Amendment: A Study of Law, Logic, Omnipotence, and Change (New York, Peter Lang Publishing).

Thompson, Paul (2001) "Is There Anything Legal About Extralegal Action? The Debate Over Dorr's Rebellion”, 36 New England Law Review: pp. 385-431.

Vile, John R (1991): "American Views of the Constitutional Amending Process: An Intellectual History of Article V”, American Journal of Legal History, vol. 35: pp. 44-69.

VILE, John R (1993) Contemporary Questions Surrounding the Constitutional Amending Process (Connecticut, Praeger).

Washington, George (1997): Writings (New York, The Library of America).

Wood, Gordon (1969): The Creation of the American Republic: 1776-1787 (New York, Norton). 